\title{
Assessment of Knowel edge and Reasons towards Substance Abuse among Community in Kebele 08, Harar Town, Eastern Ethiopia
}

Selam Bogale *1, Teshome Sosengo ${ }^{1}$

${ }^{1}$ School of Pharmacy, College of Health and Medical Sciences, Haramaya University, Ethiopia.

*Corresponding Author: Selam Bogale, School of Pharmacy, College of Health and Medical Sciences, Haramaya University, Ethiopia.

Received date: April 21, 2021; Accepted date: May 07, 2021; Published date: May 17, 2021

Citation: S Bogale, T Sosengo. (2021) Assessment of Knoweledge and Reasons towards Substance Abuse among Community in Kebele 08, Harar Town, Eastern Ethiopia. Journal of Clinical and Laboratory Research. 2(4) DOI: 10.31579/2768-0487/023

Copyright: (02021 Selam Bogale. This is an open-access article distributed under the terms of the Creative Commons Attribution License, which permits unrestricted use, distribution, and reproduction in any medium, provided the original author and source are credited.

\begin{abstract}
Background: Substance abuse is self-administration of drugs for non-medical reasons, in quantities and frequencies which may impair an individual's ability to function effectively and which may result in social, physical and emotional problems. Substance abuse is becoming a serious ongoing public health problem; it affects almost every community and family in some way. The common substances abused in most African countries including Ethiopia are alcohol, chat and tobacco

Objective:To assess Knewledge, attitude and practice toward substance abuse abuse among the community of kebele 08 community, ShenkorWereda, Harar town, Eastern Ethiopia from December 10, 2020 - February 1, 2021.

Methodology: Community based cross-sectional study using a pre-tested structured self-administered questionnaire was conducted from December10, 2020 to February 01, 2021.Simple random sampling technique was used to select 379 respondents from kebele 08, Shenkorworede, Harar town, Eastern Ethiopia residents. The data collection was done using a self-administered structured questionnaire and the data was entered and analyzed by using statistical package for social science version 24 . The result is presented in tables and figures.

Result: In this study 379 respondents were included. The $206(54.4 \%)$ of the respondents were abused to drinking alcohol, while $61.5 \%, 32.7 \%$ and $13.7 \%$ of the respondents were abused to chewing khat, smoking cigarettes and hashish respectively. The 201(53\%), 55 (14.5\%), $48(12.7 \%), 30(7.9 \%), 32(8.4 \%)$ of participants responded that smoking causes heart attack, diabetic ulcer, impotency, bladder cancer and poor wound healing respectively. The health risks of khat chewing reported by the participants were constipation 58(24.1\%), loss of appetite $34(14.1 \%)$, gastritis $33(13.7 \%)$ and teeth problem $22(9.1 \%)$ respectively.In the current study age [AOR=19, 95\% CI: 2.46-19.46] and educational status [AOR=43.19, 95\%CI: 8.42-187.84] are associated with knowledge about substance abuse.
\end{abstract}

Conclusion and Recommendation: Despite high level of knowledge regarding substance abuse, the prevalence of substance abuse among community remains high.

Key words: alcohol; cigarette; khat, knowledge; substance abuse

\section{Introduction}

Substance is anything that when taken in to the living organism that modify one or more of its functions of the body. Substances when appropriately taken appropriately can used for various functions [1]. When substances are inappropriately taken, the substance be abused and leads to various deleterious problems. Substance abuse is selfadministration of drugs for non-medical reasons, in quantities and frequencies which may impair an individual's ability to function effectively and which may result in social, physical and emotional problems [2-4]. Substance abuse is becoming a serious ongoing public health problem; it affects almost every community and family in some way. Today, there are an estimated 275 million people worldwide, which is roughly $5.6 \%$ of the global population aged 15-64 years used at least once during their life time $[5,6]$.

Social drugs use and associated problems are of current global concern. It has become an epidemic in some parts of the African region with adolescents being the main victims of health problems due to substance addiction. The common substances abused in most African countries including Ethiopia are alcohol, khat and tobacco which are reported to be abused widely among students in colleges and high schools [7-9].

Substance abuse is associated with adverse health effects such as hypertension, heart rhythm disorders, insomnia, liver toxicity, oral cancer, hypertension, spermatorrhoea and hemorrhoids, loss of appetite and 
gastrointestinal effects $[10,11]$. Medical problems associated with khat intoxication include psychiatric manifestations such as deterioration of psychophysical function and schizophrenia form psychoses. Some other khat chewers also experience anxiety, tension, restlessness, hypnogogic hallucinations, hypomania and aggressive behavior or psychosis. In addition, the combined use of alcohol and khat could increase sexual risky behavior contributing to the spread of human immunodeficiency virus (HIV) infection [12, 13].

The negative consequences of substance abuse affect not only individuals who abuse substances but also their families, friends, various businesses and government resources. Substance abuse and dependence have grave consequences for existing social systems, affecting crime rates, hospitalizations, child abuse and neglect, and rapidly consuming public funds [14]. Substance misuse is associated with psychological distress, suicide attempts functional impairment, physical ill- health and risktaking behavior

Despite such deleterious effects of substance abuse, still no study has assessed prevalence, knoweledge and reason of substance abuse among Shenkorworeda, kebele 08 communityresidents. Therefore, this study assessed the knowledgeand reasons towards substance abuse among the communities of ShenkorWoreda, kebele08, Harar town residents.

\section{Methodology}

\section{Study setting and period}

The study was conducted in Kebele 08, Shenkor, Wereda, Harar town from December10, 2020 toFebruaury 01, 2021 among ShenkorWoreda, kebele 08 residents in Harar town, Eastern Ethiopia. Harar is a city located in Eastern Ethiopia, 526kms from Addis Ababa. The total numbers of kebele of the city are 19, while the rural part of the State has 17 farmers associations. The State's size is estimated at $340 \mathrm{~km}^{2}$. Based on the 2012 census conducted by central statistics agency, the Harari national regional states' (HNRS) total population is 263,657 and 67,604 households. The percentage share of males and females is about $50 \%$ each. The urban residents of the State were 154,380 and its rural inhabitants were 109,276.

\section{Study design}

Community based cross-sectional study was conducted among ShenkoreWereda, kebele 08 community to assess knowledge and reason towards substance abuse.

\section{Population}

\section{Source and study population}

$>$ The source population was all residents of ShenkorWeredakebele 08 of Harartwon..

\section{Study population}

$>$ The study population was individuals aged greater than 15 years and living for at least six months in the town.

\section{Sample size determination}

Sample size was determined using single population proportion formula for cross-sectional study. To obtain maximum sample size at $95 \%$ certainty and a maximum discrepancy of $\pm 5 \%$ was used. The following formula was used to calculate the sample size:

$\mathrm{ni}=(\mathrm{Z} \alpha / 2)^{2} \mathrm{P}(1-\mathrm{P})$

$$
d^{2}
$$

Where;

$\mathbf{n i}=$ the desired sample size $\mathbf{p}=$ Prevalence of substance abuse among community (50\%) (since no study was conducted in the study area as far as the investigator knowledge and searching effort)

$\mathbf{Z} \boldsymbol{\alpha} / \mathbf{2}=$ critical value at $95 \%$ confidence level of certainty (1.96)

$\mathbf{d}=$ the margin of error between the sample and the population $=5 \%$

$\mathrm{n}=\frac{(1.96)^{2} \times 0.5(1-0.5)}{(0.05)^{2}}=384$

Using the above formula, sample size (ni) $=384$, since our sample population $(\mathrm{N})$ is less than 10000 (i.e) 8330 . I used the following formula to calculate the exact sample size.(nf)

$\mathrm{nf}=\mathrm{nixN} / \mathrm{ni}+\mathrm{N}$, which results in sample size of 367 . With additional $10 \%$ for contingency for non-response, the final sample size becomes 403 .

\section{Sampling procedures}

First the study kebele was selected by lottery method from 19 kebeles found in the town. Then, the sample was selected by using simple random sampling.

\section{Data collection methods and tools}

Data collectors were principal investigator (researcher) about interviewing data study participants and questioner filling.

\section{Data quality Control}

In order to assure data quality, high emphasis was given to minimize errors using the following strategies: the questionnaire was pretested and subsequent correction and modification was done, and proper instruction was given before the survey was started. The collected data was reviewed and checked for completeness before data entry.

\section{Data processing and analysis}

The collected data was coded, entered and analyzed with SPSS version 20 program and the result is presented by tables and figures.

\section{Ethical considerations}

The study was carried out after letter of permission obtained from school of pharmacy, Haramaya University College of Health and Medical Science.Confidentiality wasassured and full written informed consent wasobtained from all participants before actual data collection.

\section{Operational definitions}

Alcoholic drinks: any drink like "tela," "tej," "katicala/areke", beer, wine or other drinks that can cause intoxication

Attitude: Ways of thinking or feeling, which will drive a person to do or not to do things.

Illicit (illegal) drugs: Drugs which are forbidden by law such as cocaine, heroin, hashish, cannabis, ganja, and marijuana.

Knowledge: Information and skills acquired through experience or education. The participant will be categorized depending on their level of knowledge as per level of correct answer to 10 questions to assess knowledge as (Awole et al, 2015)

- Highly knowledgeable; if he/she answer (7-10) out of 10 questions

- Fairly knowledgeable; if he/she answer (4-6) out of 10 questions

- Not knowledgeable; if he/she answer (less than 3 or 3 ) out of 10 questions 
Lifetime prevalence of alcohol drinking: the proportion of respondents who had ever used alcoholic drinks in their life time irrespective of the amount and type

Life time prevalence of khat chewing: the proportion of respondents who had ever chewed khat in their life time

Substances: Any non-medical drugs used by study subjects such as alcohol, khat, tobacco, cannabis, heroin, cocaine, and marijuana to alter their mood or behaviour

Substance abuse: A condition in which the person uses a drug over and over again, in ways that hurt their health.

\section{Result}

\section{Socio-demographic characteristics}

Out of the total403 community members invited to fill the questionnaire, the 379 respondents participated in the study with a response rate of $94.5 \%$. The $211(55.7 \%)$ and $168(44.3 \%)$ respondents were male and female respectively. Most of the study participants belong to an age group of $15-24$ years $(32.5 \%)$ and 25-34years $(25.6 \%)$.

The $10.8 \%$ of the participants were illiterate and $26.6 \%$ have completed primary education. With regard to occupation $110(29 \%)$ of the respondents are unemployed and $89(23.55)$ of the respondents were government employees. The $172(45.4 \%)$ and $158(41.7 \%)$ of the respondents were orthodox and Muslim respectively by their religion.

With respect marital status, the $167(44.1 \%)$ and $166(43.8 \%)$ were single and married. The monthly household income of the majority $(59.9 \%)$ of the participants was below 1000 Ethiopian birr (Table 1).

\begin{tabular}{|c|c|c|}
\hline Variable & Frequency & Percentage (\%) \\
\hline Sex & & \\
\hline Male & 211 & 55.7 \\
\hline Female & 168 & 44.3 \\
\hline Age & & \\
\hline $15-24$ & 123 & 32.5 \\
\hline $25-34$ & 97 & 25.6 \\
\hline $35-44$ & 61 & 16.1 \\
\hline $45-54$ & 56 & 14.8 \\
\hline$>55$ & 42 & 11.1 \\
\hline
\end{tabular}

\begin{tabular}{|c|c|c|}
\hline Variable & Frequency & Percentage \\
\hline \multicolumn{3}{|l|}{ Educational status } \\
\hline $\begin{array}{l}\text { Illiterate } \\
\text { Read and write } \\
\text { Primary school } \\
\text { Secondary school } \\
\text { Collage/University }\end{array}$ & $\begin{array}{r}41 \\
82 \\
101 \\
83 \\
72\end{array}$ & $\begin{array}{c}10.8 \\
21.6 \\
26 . \\
21.9 \\
19\end{array}$ \\
\hline \multicolumn{3}{|l|}{ Occupation } \\
\hline $\begin{array}{l}\text { Government } \\
\text { Private sector } \\
\text { Self employed } \\
\text { Daily labor } \\
\text { I have no work }\end{array}$ & $\begin{array}{c}89 \\
67 \\
81 \\
32 \\
110\end{array}$ & $\begin{array}{c}23.5 \\
17.7 \\
21.4 \\
8.4 \\
29\end{array}$ \\
\hline \multicolumn{3}{|l|}{ Religion } \\
\hline $\begin{array}{l}\text { Orthodox } \\
\text { Muslim } \\
\text { Protestant } \\
\text { Catholic } \\
\text { Other* }\end{array}$ & $\begin{array}{c}172 \\
158 \\
40 \\
5 \\
4\end{array}$ & $\begin{array}{c}45.4 \\
41.7 \\
10.6 \\
1.3 \\
1.1\end{array}$ \\
\hline \multicolumn{3}{|l|}{ Marital status } \\
\hline $\begin{array}{c}\text { Single } \\
\text { Married } \\
\text { Divorced } \\
\text { Widowed }\end{array}$ & $\begin{array}{c}167 \\
166 \\
28 \\
18\end{array}$ & $\begin{array}{c}44.1 \\
43.8 \\
7.4 \\
4.7\end{array}$ \\
\hline \multicolumn{3}{|l|}{ Monthly income } \\
\hline $\begin{array}{c}<1000 \\
1000-5000 \\
5000-10000 \\
>10000\end{array}$ & $\begin{array}{c}227 \\
117 \\
23 \\
12\end{array}$ & $\begin{array}{c}59.9 \\
30.9 \\
6.1 \\
3.2\end{array}$ \\
\hline Other*: No religion & & \\
\hline
\end{tabular}


Practice of substance abuse

The majority, 206(54.4\%) of the respondents were abused to drinking of alcohol. The $233(61.5 \%)$ and $135(35.6 \%)$ of the respondents were abused to chewing chat and cigarettes smoking respectively. Significant proportion, (13.7\%) of the study participants were abused to smoking of marijuana /hashish (Table 2).

\begin{tabular}{|l|l|c|}
\hline Variable & Frequency & Percentage (\%) \\
\hline Abuse of alcoholic & & \\
Yes & 206 & 54.4 \\
No & 173 & 45.6 \\
& & \\
\hline Abuse of khat chewing & & \\
\hline Yes & 233 & 61.5 \\
\hline No & 146 & 38.5 \\
Abuse of cigarette smoking & 135 & 35.6 \\
$\quad$ Yes & 244 & 64.4 \\
No & & \\
Abuse of marijuana /hashish & 52 & 13.7 \\
No & 327 & 86.3 \\
\hline
\end{tabular}

Table 2: Prevalence of substance abuse among the study participants kebele 08, Harar town, East Ethiopia, February 2021.

\section{Reason of substance abuse}

Different reasons were mentioned by the participants about abuse of the substances. The most common reasons mentioned for the abuse of chat chewing were to increase work or academic performance $73(31.3 \%)$, followed by to stay awake 50(21.5\%). The majority of the respondents replied that they are abused to alcohol to get personal pleasure $101(49 \%)$ and due to peer influence (24.3\%) (Table 3).

\begin{tabular}{|c|c|c|c|}
\hline Variable & Reason for abuse & Freq* & $(\%)^{*}$ \\
\hline Khat Chewing & $\begin{array}{l}\text { To increase work or academic performance } \\
\text { Due tofamily chewing habit } \\
\text { To stay awake } \\
\text { Due to peer pressure } \\
\text { To get personal pleasure } \\
\text { To increase work or academic performance } \\
\text { +family chewing habit +to stay awake } \\
\text { To stay awake +peer pressure to get } \\
\text { Personal pleasure } \\
\text { All }\end{array}$ & $\begin{array}{l}73 \\
20 \\
50 \\
26 \\
32 \\
12 \\
15 \\
5\end{array}$ & $\begin{array}{r}31.3 \\
8.6 \\
21.5 \\
11.2 \\
13.7 \\
5.2 \\
6.4 \\
\\
1.3 \\
\end{array}$ \\
\hline Alcohol drinking & $\begin{array}{l}\text { To get personal pleasure } \\
\text { Due to peer influence } \\
\text { Due to academic work dissatisfaction } \\
\text { To be sociable } \\
\text { To increase pleasure during sexual practice } \\
\text { To get personal pleasure + } \\
\text { due to peer influence }+ \\
\text { due to academic work } \\
\text { dissatisfaction +to be sociable }\end{array}$ & $\begin{array}{c}101 \\
50 \\
16 \\
25 \\
2 \\
12\end{array}$ & $\begin{array}{l}49 \\
24.3 \\
7.8 \\
12.1 \\
1 \\
5.8\end{array}$ \\
\hline Freq*: Frequency & $\%$ : Percentage & & \\
\hline
\end{tabular}

Table 3: Reason for substance abuse for the study participant'skebele 08, Harar town, Eastern Ethiopia, February 2021.

Knowledge toward substance abuse

The $324(85.8 \%)$ of the respondents were adequately knowledgeable and 54(14.2\%) were inadequately knowledgeable and not knowledgeable respectively about effects of substance abuse (Figure 1 ). 




Figure 1: Study participant's knowledge about substance abuse kebele 08, Harar town, Eastern Ethiopia, February, 2021.

Knowledge towards health problems caused substance abuse

The health risks of khat chewing reported by the participants were constipation $58(24.1 \%)$ loss of appetite $34(16 \%)$, gastritis $33(13.7 \%)$ and teeth Problem 22(9.1\%), respectively (Table 4).
The 201(53\%), $55(14.5 \%), \quad 48 \quad(12.7 \%), 30(7.9 \%), 32(8.4 \%)$ of participants responded that smoking causes heart attack, diabetic ulcer, impotency, Bladder cancer and poor wound healing respectively (Figure 2).

\begin{tabular}{|l|c|c|}
\hline Variable & Frequency & Percentage (\%) \\
\hline Health risks caused by khat chewing & & \\
\hline Constipation & 58 & 24.2 \\
Loss of appetite & 34 & 14.1 \\
Gastritis & 33 & 13.7 \\
Teeth problem & 22 & 9.1 \\
Decrease in sexual desire & 15 & 6.2 \\
Constipation+ loss of appetite+ & 30 & 12.4 \\
Gastritis + teeth problem & 31 & 12.9 \\
All & 18 & 7.5 \\
No problem & & \\
\hline
\end{tabular}

Table 4: Health risks of khat chewing mentioned by study participants kebele 08, Harar town, eastern Ethiopia, February 2021.

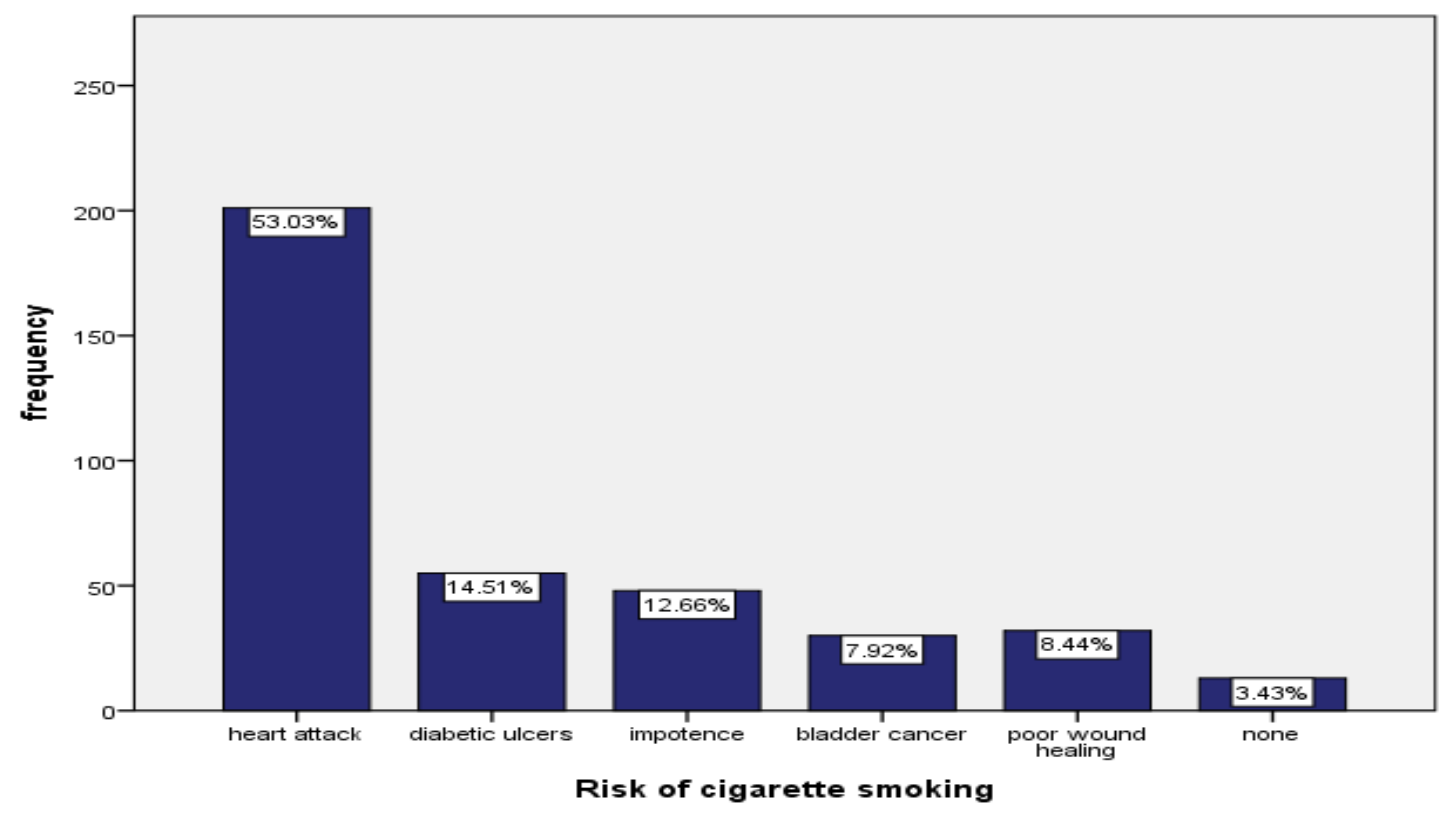




\section{Determinants of treatment outcomes}

In the bivariate logistic regression association of sex, educational status and age towards knowledge about substance abuse was assessed. Accordingly sex, educational status and age were found to be significantly associated with knowledge about substance abuse with [p value $<0.05$ ).
In multivariate logistic regression, respondents with age of less than 45 years were 19 times more likely to have adequate knowledge about substance abuse [AOR=19,95\% CI: 2.46-19.46] compared to respondents whose age is above 45 years and respondents who are literate are 43 times more likely to have adequate knowledge about substance abuse [AOR=43.19, 95\%CI: 8.42-187.84] (Table 5).

\begin{tabular}{|c|c|c|c|c|c|}
\hline \multirow[t]{2}{*}{ Variable } & & & \multicolumn{2}{|c|}{ Odd ratio $(95 \% \mathrm{CI})$} & \multirow[t]{2}{*}{ P-value } \\
\hline & $\begin{array}{l}\text { Adequate } \\
\text { knowledge }\end{array}$ & $\begin{array}{l}\text { Inadequate } \\
\text { knowledge }\end{array}$ & COR & AOR & \\
\hline \multicolumn{6}{|l|}{ Sex } \\
\hline Male & 181 & 30 & $2.76(1.4-6.57)$ & $0.381(0.147-1.654)$ & $0.03 *$ \\
\hline Female & 144 & 24 & 1 & 1 & \\
\hline \multicolumn{6}{|l|}{ Age } \\
\hline $\begin{array}{c}15-45 \\
>45\end{array}$ & $\begin{array}{c}270 \\
55\end{array}$ & $\begin{array}{l}11 \\
43\end{array}$ & $\begin{array}{c}0.063(0.017-0.253) \\
1\end{array}$ & $\begin{array}{c}19(2.46-19.46) \\
1\end{array}$ & $0.002 *$ \\
\hline \multicolumn{6}{|c|}{ Educational Status } \\
\hline Illiterate & 6 & 35 & $0.101(0.020-0.507)$ & $43.19(8.42-187.84)$ & $0.003^{*}$ \\
\hline Literate & 319 & 19 & 1 & 1 & \\
\hline
\end{tabular}

Table 5: Predictors of knowledge about substance abusestudy participant'skebele 08, Harar town, Eastern Ethiopia, February 2021

COR-Crude Odds Ratio, AOR-Adjusted Odds Ratio, * statistically significant, CI-Confidence Interval

\section{Discussions}

In this study three hundred seventy-nine (379) respondents were included, of which $211(55.7 \%)$ and $168(44.3 \%)$ respondents were male and female respectively.

In the present study, the $61.5 \%$ of the respondents were abused of chewing khat. This result is higher than a report from Sebata town, Ethiopia 52.3\% [15],jazan region of Saudi Arabia (21.46\%) [16] and Gondar, Ethiopia (42\%) [17].The discrepancy of the results may be due differences in sample sizes and culture among the study participants.

In the current study the major reasons given by the study participants for chewing khat were to increase academic (work) performance $(31.3 \%$ ) and to stay awake $(21.55 \%)$. The is in opposite to report of study done among students of a college in Gondar, Ethiopia which revealed that the majority of the respondents stated that their reason for Khat chewing was for concentration $(62.3 \%)$ followed by for entertainment and relaxation $(36.9 \%)$ [17]. This result is significantly higher than study done in Meru Kenya among secondary students reported that 58(28.9\%), $16(8 \%), 5$ $(2.5 \%)$ and $5(2.5 \%)$ reported that they chew Khat for reasons getting concentration, entertainment, get good health and relief from stress respectively [18].

The $54.4 \%$ of the study participants were abused to alcohol consumption. This result is significantly higher than study report of study done in Jimma town, Ethiopia $(11.5 \%)$ andin Iran $(33 \%)$ [19, 20]. This variation could be due difference in sample size, geographical and cultural difference among the participants. Current study finding is lower than study report of study done in Mekelle town, Ethiopia in which $64.9 \%$ of the respondents were addicted to alcohol consumption [13].

The prevalence of cigarette smoking in this study is $35.6 \%$. This result is significantly higher than study done in Mekelle University, Ethiopia and study conducted among Shahroud University students in 29.55 and $20 \%$ respectively of the respondents were addicted to cigarette smoking [13, 20].This variation may be due difference in the, cultural and educational status of the study participants.

In the present study the $85.8 \%$ and $14.2 \%$ of participants were adequately and inadequately knowledgeable about substance abuse and its harmful effect on health.The current study result is almost in line with result of another study done in India, in which $84 \%$ were have knowledge regarding harmfulness of substance abuse [21]. Our study finding is higher than to result of a study carried out in International Islamic University of Malaysia, in which the $63.5 \%$ of the respondents have good knowledge about the consequences of substance abuse [14]. The possible explanation for this variation could be the socio demographic and cultural variation.

Age and educational status of the respondents was found to be associated with knowledge about substance abuse. In the current study respondents with age of less than 45 years were 19 times more likely to have adequate knowledge about substance abuse[AOR=19, 95\% CI: 2.46-19.46] compared to respondents whose age is above 45 years and respondents who are literate are 43 times more likely to have adequate knowledge about substance abuse [AOR=43.19, 95\%CI: 8.42-187.84],

In this study majority of the respondents reported that constipation $59(24.2 \%)$ and loss of appetite $39(16 \%)$ were health risks of khat chewing. This is in line with study done in Sebata, Ethiopia and Kaffa Zone, Ethiopia [15].The current result is in opposite to a study report of a study done inMeru Kenya, in which the $37.8 \%$ and $20.9 \%$ respondents report harmful effects of Chewing Khat on teeth and other body systems [18].

Conclusion and Recommendation: Despite high level of knowledge regarding substance abuse, the prevalence of substance abuse among community remain high.Thus concerned bodies like health bureaus and non-governmental organizations should take measure to decrease prevalence of substance abuse among the community.

\section{Acknowledgement}

The author acknowledges Haramaya University College of health and medical Sciences for all positive co-operations for the undertaking of this study.

\section{Declarations}

Consent to publish: Not applicable

Funding: None 
Competing interests: The author declare no competing interest.

Conflict of Interest: The authors declare no conflict of interest.

\section{Author's contribution}

Author SelamBogale involved in the conception and design of the study, participated in the literature searches, analyzed data and wrote the manuscript. Both the authors approved the final manuscript.Author TeshomeSosengoinvolved in the conception and design of the study, participated in the literature searches, supervised data collection and analyzed data.

Availability of data: All the data are available with the corresponding author, SelamBogale.

\section{References}

1. Turki Y., Saleh, S., Albaik S., Barham Y., de Vrie D and Shahin $\mathrm{y}$ et al. (2020) Assessment of the knowledge, attitudes, and practices (KAP) among UNRWA* health staff in Jordan concerning mental health programme pre-implementation: a cross-sectional study. Int J Ment Health Syst . 14(54): 1-10.

2. KassaAlemu BK and Biru TT. (2019) Health Care Professionals' Knowledge, Attitude, and Practice towards Adverse Drug Reaction Reporting and Associated Factors at Selected Public Hospitals in Northeast Ethiopia: A Cross-Sectional Study. BioMed Research International.

3. Mary M. Ramos, Rachel A. Sebastian, Mary Murphy, Kristin Oreskovich\& Timothy P. (2017) Condon (2017) Adolescent substance use: Assessing the knowledge, attitudes, and practices of a school-based health center workforce. Substance Abuse. 38(2): 230-236.

4. Park K. (2013) Mental Health: Text Book of Preventive and Social medicine, 22nd ed. Jabalpur: BanarsidasBhanot Publishers: PP.782-796.

5. Abdu N. (2013) The impacts of khat (chat) among active sport participants' the case of Kaffa zone, Bonga town in some selected football clubs. MSC thesis.

6. UNODC. (2018) World drug report, New York united Nations. Vienna, Austria.

7. Kalayu, M., Andualem, M and Yeshigeta, G. (2009) Effect of substance use on academic achievement of health officer and medical students of Jimma University, Southwest Ethiopia.Ethiopian Journal of health science. 19(3):155-163.

8. Jaber D., Bulatova N, Suyagh M, Yousef AM and Wazaify M. (2015) Knowledge, Attitude and Opinion of Drug Misuse and Abuse by Pharmacy Students: A Cross-Sectional Study in Jordan. Tropical Journal of Pharmaceutical Research. 14 (8): 1501-1508.

9. Kotina, S., Sawant, G.V and Kokiwar, P.R. (2016) A study to determine causes, prevalence and knowledge regarding consequences of substance abuse: a community based cross sectional study. Int J Community Med public health. 3:730-734.
10. Shalaby SF and Soliman MA. Knowledge, attitude, and practice of medical students regarding smoking and substance abuse, Cairo University, Egypt. Journal of the Egyptian Public Health Association. 94:11.

11. Priyadarshini SR, Sahoo PK, Jena D, Panigrahi R, Patnaik S, Mohapatra A. (2019) Knowledge, attitude and practice of dental professionals towards substance use. J IntSoc Prevent Communit Dent. 9:65-71.

12. Molobe ID. Knowledge, Attitude and Practice on Drug Abuse among Sports Men and Women in Lagos State, Nigeria. International Journal of Medicine and Medical Sciences. 1018; 2 (3): 077-085.

13. Awell, Y, Yerra, R., Tadele, E., Getu, K., Dagim, A and Hailekiros, G. (2016) Socio-economic and health effects of Khatchewing in Mekelle, Tigray Region. Ethiopia. IJPPR. 8(1): $11-22$

14. Nurul, I.A., Nor, A.A., Nor, I.R and Mainul, H. (2016) Knowledge, attitude and practice towards smoking among International Islamic University Malaysia Kuantan communities. International Medical Journal Malaysia. 15(2): 19-25

15. Etana BM. (2018) Economic and Social Impacts of Khat (Catha edulis Orsk) Chewing Among Youth in Sebeta Town, Oromia Ethiopia. Biomedical Statistics and Informatics. 3(2): 29-33.

16. Ageely HM. (2009) Prevalence of Khat chewing in college and secondary (high) school students of Jazan region, Saudi Arabia. Harm Reduct J. 6 (11):3.

17. Teni FS, Surur AS, Hailemariam A, Aye A, Mitiku G, Gurmu AE, et al. (2015) Prevalence, reasons, and perceived effects of Khat chewing among students of a college in Gondar town, Northwestern Ethiopia: A cross-sectional study. Ann Med Health Sci Res. 5:454-460.

18. Emma K. (2013) khat chewing practices and knowledge of oral health effects among students in two boys' secondary schools in meru county Kenya. MSC thesis.

19. Ayenew, M., Kabeta, T. \&Woldemichael, K. (2020) Prevalence and factors associated with substance use among street children in Jimma town, Oromiya national regional state, Ethiopia: a community based cross-sectional study. Subst Abuse Treat Prev Policy.; 15(61) 1-9.

20. Vakilian K, Mousavi SA, Keramat A, Chaman R. (2019) Experience Assessment of Tobacco Smoking, Alcohol Drinking, and Substance Use Among Shahroud University Students by Crosswise Model Estimation- the Alarm to Families. The Open Public Health Journal. 12: 33-37.

21. Kotina S., Sawant G V and Kokiwar P R. (2016) A study to determine causes, prevalence and knowledge regarding consequences of substance abuse: a community based cross sectional study. Int J Community Med public health. 3:730-734. 